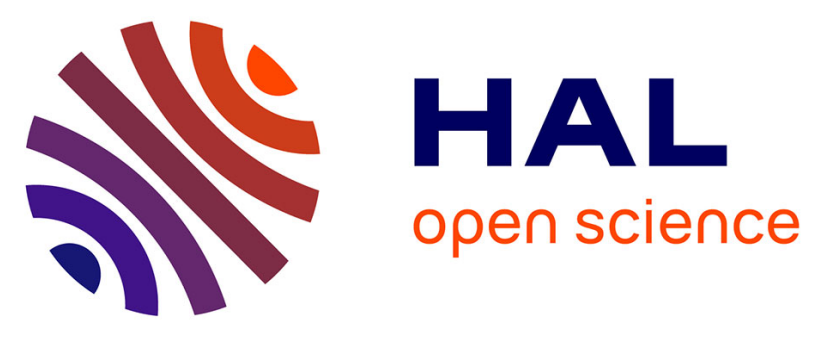

\title{
Loss of von Willebrand factor high-molecular-weight multimers at acute phase is associated with detectable anti-ADAMTS13 IgG and neurological symptoms in acquired thrombotic thrombocytopenic purpura
}

Nicolas Béranger, Sandrine Benghezal, Sylvaine Savigny, Sophie Capdenat, Bérangère S. Joly, Paul Coppo, Alain Stepanian, Agnès Veyradier

\section{To cite this version:}

Nicolas Béranger, Sandrine Benghezal, Sylvaine Savigny, Sophie Capdenat, Bérangère S. Joly, et al.. Loss of von Willebrand factor high-molecular-weight multimers at acute phase is associated with detectable anti-ADAMTS13 IgG and neurological symptoms in acquired thrombotic thrombocytopenic purpura. Thrombosis Research, 2019, 181, pp.29 - 35. 10.1016/j.thromres.2019.07.012 . hal-03487616

\author{
HAL Id: hal-03487616 \\ https://hal.science/hal-03487616
}

Submitted on 20 Dec 2021

HAL is a multi-disciplinary open access archive for the deposit and dissemination of scientific research documents, whether they are published or not. The documents may come from teaching and research institutions in France or abroad, or from public or private research centers.
L'archive ouverte pluridisciplinaire HAL, est destinée au dépôt et à la diffusion de documents scientifiques de niveau recherche, publiés ou non, émanant des établissements d'enseignement et de recherche français ou étrangers, des laboratoires publics ou privés.

\section{(ㄷ)(1) $\$$}

Distributed under a Creative Commons Attribution - NonCommerciall 4.0 International 


\section{Manuscript TR-D-19-00199. R1 version 06-25-2019}

Loss of von Willebrand factor high-molecular-weight multimers at acute phase is associated with detectable anti-ADAMTS13 IgG and neurological symptoms in acquired thrombotic thrombocytopenic purpura.

Running title: Von Willebrand factor high-molecular-weight multimers in acquired thrombotic thrombocytopenic purpura

Nicolas Béranger ${ }^{1,2}$, Sandrine Benghezal ${ }^{1,2}$, Sylvaine Savigny ${ }^{1,2}$, Sophie Capdenat ${ }^{1,2}$, Bérangère S. Joly ${ }^{1,2}$, Paul Coppo ${ }^{3,4}$, Alain Stepanian ${ }^{1,2}$, Agnès Veyradier ${ }^{1,2}$

'Service d'Hématologie Biologique, Hôpital Lariboisière, Assistance Publique-Hôpitaux de Paris, Paris, France ; ${ }^{2}$ EA3518, Institut Universitaire d'Hématologie Saint Louis, Université Paris Diderot, Paris, France ; ${ }^{3}$ Service d'Hématologie - Centre National de référence des MicroAngiopathies Thrombotiques, Hôpital Saint-Antoine, Assistance Publique-Hôpitaux de Paris, Paris, France ; ${ }^{4}$ Sorbonne Universités, Université Paris 6, Paris, France.

\section{Key words}

Thrombotic thrombocytopenic purpura. ADAMTS13. Von Willebrand factor. Multimer. Collagen.

\section{Correspondence}

Pr Agnès Veyradier, MD, PhD, Service d'Hématologie Biologique, Hôpital Lariboisière, Assistance Publique-Hôpitaux de Paris, 2 rue Ambroise Paré, 75010 Paris, France ; telephone : +33149956411; fax : +33149956397 ; e-mail : agnes.veyradier@aphp.fr

Word count: 3722

\section{Tables}

\section{Figures}




\begin{abstract}
Introduction: Thrombotic thrombocytopenic purpura (TTP) is a rare life threatening thrombotic microangiopathy caused by a severe functional deficiency of ADAMTS13, most frequently due to autoantibodies to ADAMTS13, thus termed acquired autoimmune TTP. ADAMTS13 specifically regulates the adhesive activity of von Willebrand factor (VWF) by cleaving its high-molecular-weight multimers (HMWM). We investigated whether VWF-HMWM level at acute phase of TTP could be a predictive factor for morbidity.

Material and methods: We gathered clinical and biological data from a cohort of 114 patients with acquired TTP at acute phase. VWF-HMWM were assessed by electrophoretic analysis and by an ELISA measuring the capacity of VWF to bind to collagen (VWF:CB), and linear correlation between these two methods was carried out. We cross-referenced clinical and biological data with VWF-HMWM levels.

Results: VWF-HMWM levels were heterogeneous, but half of our patients were below normal range ( $50 \%$ if assessed by electrophoresis; $47.4 \%$ if assessed by ELISA). The correlation study between electrophoresis and ELISA reached statistical significance $\left(r^{2}=0.5979 ; p\right.$ $<0.0001$ ). Statistical analysis showed that loss of VWF-HMWM as assessed by VWF:CB<70 $\mathrm{IU} / \mathrm{dL}$ is associated with detectable anti-ADAMTS13 antibodies, severe neurological symptoms and thrombocytopenia $(p<0.05)$

Conclusion: Our results confirm that VWF-HMWM can be satisfactorily assessed by VWF:CB, much easier to perform than electrophoresis. The association highlighted between loss of VWF-HMWM, detectable anti-ADAMTS13 lgG and neurological symptoms may offer new insights to understanding the pathophysiology of acquired auto-immune TTP.
\end{abstract}




\section{Introduction}

Thrombotic microangiopathies (TMA) are rare, life threatening diseases defined by the association of mechanical hemolytic anemia with erythrocyte fragmentation, consumption thrombocytopenia and organ failure of variable severity. Thrombotic thrombocytopenic purpura (TTP) is a form of TMA specifically caused by a severe functional deficiency of ADAMTS13 (A Disintegrin And Metalloprotease with ThromboSpondin type 1 repeats, member 13), the specific von Willebrand factor (VWF)-cleaving protease [1]. At the acute phase of TTP, the severe functional deficiency of ADAMTS13 activity (below $10 \%$ of normal) leads to the accumulation of ultralarge hyper-adhesive VWF multimers in plasma, which spontaneously bind to platelets, hence consumption thrombocytopenia, and form VWF-rich platelet microthrombi on the surface of which red blood cells are fractured into schistocytes [2]. These microthrombi obstruct blood flow in the microcirculation, thus causing multivisceral ischemia. After effective therapy, the ischemia symptoms and the bicytopenia disappear, defining remission phase, during which patients still require periodic blood cell count and ADAMTS13 activity monitoring to predict any relapse [3]. TTP is an acquired disease in most cases and can also be hereditary in a few cases, due to recessively inherited mutations of the ADAMTS13 gene (Upshaw-Schulman Syndrome, USS) [4]. TTP is termed acquired autoimmune when due to autoantibodies against ADAMTS13 [5].

Acquired TTP is a medical emergency requiring rapid management. Frequent clinical features include fever, neurological symptoms (such as headache, confusion, convulsions, coma or brain ischemia) and cardiac ischemia, but clinical presentation is widely heterogeneous and TTP diagnosis can be challenging [6, 7].

Finding new parameters that could explain the variability of clinical presentation ac acute phase of TTP could be useful, either as part of new diagnosis algorithms or as prognostic tools. In this study, we focused on VWF multimeric analysis and hypothesize that clinical or biological features exhibited at acute phase of TTP could partially depend on VWF-HMWM levels. VWF-HMWM are known to be the most adhesive platelet-binding fraction of all VWF multimers, and they are crucial to maintain functionality of VWF [8]. This is highlighted in von Willebrand Disease (VWD) type 2A, a subtype of VWD characterized by decreased VWFdependent platelet adhesion due to selective loss of VWF-HMWM usually resulting from an increased sensitivity to cleavage by ADAMTS13 [9]. VWF multimeric analysis is usually performed using electrophoresis as the reference method, and it can be helpful to diagnose VWD2A. However, electrophoresis is time consuming and technical to carry out [10]. Rather than this complex in-house method, we chose to assess HMWM through two approaches: i) semi-automated electrophoresis using SDS-agarose gel and immunochemical revelation and 
ii) ELISA method based on the capacity of VWF to bind to human type III collagen (VWF:CB) as VWF:CB not only assesses the integrity of VWF collagen binding domains ( $A 1$ and $A 3$ ) but also shows preferential binding to VWF-HMWM [11].

While TTP is characterized by an excess of ultralarge hyperadhesive VWF-HMWM, a previous study showed that plasma VWF multimeric analysis in TTP patients at acute phase was very heterogenous [12], with roughly a third each of selective loss, excess or normal fraction of VWF-HMWM and no apparent connection to clinical or biological features. Moreover, VWF antigen (VWF:Ag) levels are usually high but vary greatly amongst TTP patients, probably in accordance with the level of endothelial lesion.

In this study, we chose to rely on VWF-HMWM levels (expressed in IU/dL), as the product of HMWM fraction assessed by electrophoresis and VWF:Ag levels, and look into whether a specific apparent decreased VWF-HMWM level could be associated with higher morbidity. To support that hypothesis, we also performed VWF:CB as the reflect of VWF-HMWM levels and cross-referenced both parameters to clinical and biological data gathered from a cohort of 114 TTP patients.

\section{Material and methods}

\section{Patients.}

Since 2000, all patients in France with a presumptive diagnosis of TMA (defined as the presence of microangiopathic hemolytic anemia with hemoglobin level $<12 \mathrm{~g} / \mathrm{dL}$ with or without presence of schistocytes, and thrombocytopenia $<150 \times 10^{9} / \mathrm{L}$ with or without ischaemic manifestations) have been enrolled in the registry of the National Reference Center for TMA (Health Ministry National Plan for Rare Diseases) and have been investigated for ADAMTS13 by the French reference laboratory for TMA.

We studied 114 patients (109 adults and 5 children, $4<15$ years old and $1>15$ years old) with well documented acquired TTP at acute phase prospectively enrolled from 2006 to 2010 as part of a clinical research program. Nine patients with USS at remission phase, thus presenting a constant excess of VWF-HMWM through genetic deficiency of ADAMTS13 were used as controls. Inclusion criteria comprise clinical diagnosis of TTP, severe deficiency of ADAMTS13 activity (<10\%), hemoglobin level $<10 \mathrm{~g} / \mathrm{dL}$ and/or platelet count $<150 \times 10^{9} / \mathrm{L}$, while exclusion criteria include cancer, HIV and organ graft. Clinical and biological data were collected after extensive analysis of medical records, including 8 to 14 years of follow-up (relapse and/or death). Neurological symptoms were particularly looked into: symptoms such as headaches or confusion were considered mild neurological symptoms, while seizures, coma, focal deficiency or two (or more) neurological symptoms were labelled severe. Cerebral ischemia was assessed by clinical presentation and magnetic resonance imaging. 
Written informed consent was obtained from all patients according to the Declaration of Helsinki. The study was approved by the Ethics Committee of Hospital Pitié-Salpêtrière (Paris. France). The study is registered at www.clinicaltrials.gov as number NCT00426686, at the Health Authority and by the French Ministry of Health as number P051064/PHRC AOM05012.

Venous blood was collected at the time of enrollment (acute phase) before any treatment, into $1: 10$ final volume of $3.8 \%$ sodium citrate. A normal pooled plasma (14 healthy volunteers) was used as normal control for all biologic assays.

\section{ADAMTS13 activity assay}

ADAMTS13 activity was assessed using the method of Kokame et al [13] using commercial recombinant FRETS-VWF73 peptide (Peptide Institute, Osaka, Japan) according to the manufacturer's instructions. Normal range is between $50 \%$ and $150 \%$.

\section{VWF:Ag measurement}

Plasma VWF:Ag was measured using the ASSERACHROM® VWF:Ag ELISA kit (Stago, Asnières-sur-Seine, France) according to the manufacturer's instructions. The normal range is $50 \mathrm{lU} / \mathrm{dL}-150 \mathrm{IU} / \mathrm{dL}$.

\section{Multimeric distribution of VWF}

The assessment of multimeric distribution of VWF was carried out using the HYDRAGEL von WILLEBRAND MULTIMERS $\AA$ agarose gel on the semi-automated system HYDRASIS $2 \AA$ and using the software PHORESIS version 8.6.3 for densitometry analysis (Sebia, Lisses, France) according to the manufacturer's instructions. High moleculair weight multimers are defined as all peaks beyond the 10th peak (10th mer). Given the technical performances of the electrophoretic assay we used, we lowered the cut-off value to the 8th peak and analyzed collectively all peaks beyond as high molecular weight multimers. VWF-HMWM (expressed in $\mathrm{IU} / \mathrm{dL}$ ) were then calculated as the product of VWF:Ag and HMWM percentage. The mean HMWM fraction was validated from 24 assessments of a normal pool carried out over 20 electrophoretic assays.

\section{VWF:CB measurement}

Plasma VWF:CB measurement was assessed using the ASSERACHROM® VWF:CB ELISA kit (Stago, Asnières-sur-Seine, France) according to the manufacturer's instructions. The normal range, as stated by the French National Reference Center for von Willebrand Disease, is $70 \mathrm{IU} / \mathrm{dL}-100 \mathrm{IU} / \mathrm{dL}[10]$. 


\section{Statistical analysis.}

Categorical variables were compared with $\mathrm{X}^{2}$ or Fisher's exact tests as appropriate. Continuous variables were compared with the non-parametric Mann-Whitney $U$ test. Linear regression was performed using Pearson's formula. All tests were two-sided and statistical significance was set at $p<0.05$. Statistical analysis was performed using GraphPad Prism $\circledast$ version 7.00 (GraphPad Software. La Jolla. California. United States).

\section{Results}

\section{I) Characteristics of the cohort at presentation}

The demographic, clinical and biological features of our 114 patients with acquired TTP are presented in Table 1. Median age in our cohort was 35.5 years (range $1.5-71.3$ ) with $67.5 \%$ of female patients. More than two third of our patients had idiopathic TTP $(69.3 \%)$ while nonidiopathic TTP $(30.7 \%)$ were mostly associated with specific clinical contexts such as autoimmune disease $(14.9 \%)$, non-HIV infection $(7.9 \%)$ or pregnancy $(10.9 \%$ of women aged 15 to 45). Clinical presentation was heterogenous, but neurological abnormalities were present in $59.6 \%$ of patients, ranging from minor such as headaches $(33.9 \%)$ or confusion $(20.2 \%)$ to severe symptoms like seizure $(1.8 \%)$, coma $(6.4 \%)$ or focal deficiency $(7.3 \%)$, with $10.0 \%$ of patients presenting at least two neurological symptoms. Most adult patient did not exhibit renal failure, with median creatinine level at $114 \mu \mathrm{mol} / \mathrm{L}$ ( $\min .66-\max .312 \mu \mathrm{mol} / \mathrm{L}$ ), however $21.1 \%$ of patients had proteinuria and $14.7 \%$ hemoglobinuria. Out of the 5 pediatric patients studied, only three records contained creatinine level: two were within normal range for the age of the patient, and only one pediatric patient exhibited high creatinine level (192 $\mu \mathrm{mol} / \mathrm{L})$. The biological data revealed that a vast majority of patients had detectable antiADAMTS13 IgG (84.8\%), consistent with auto-immune acquired TTP. Microangiopathic hemolytic anemia and/or thrombocytopenia were found in all patients with median hemoglobin at $7.8 \mathrm{~g} / \mathrm{dL}$ ( $\min .3 .2-\max .15 .8 \mathrm{~g} / \mathrm{dL}$ ) and median platelet count at $15 \times 10^{9} / \mathrm{L}$ (min. 2 - max. $251 \times 10^{9} / \mathrm{L}$ ). Only 2 patients did not have thrombocytopenia, but both had microangiopathic hemolytic anemia. Schistocytes were detected on blood smears in $89.7 \%$ of patients. Thirty-one patients (27.2\%) had at least one relapse reported during follow-up, and only one patient $(0.9 \%)$ died of TTP. 
Table 1. Demographic, clinical and biological characteristics of the cohort of 114 patients with acquired TTP.

\begin{tabular}{|c|c|}
\hline Continuous variables & 114 patients \\
\hline Age (years)* & $35.5(1.5-71.3)$ \\
\hline Sex & 77 females -37 males; Sex ratio $2 F / 1 M$ \\
\hline Hemoglobin level (g/dL) & $7.8(3.2-15.8)$ \\
\hline Platelet count $\left(\times 10^{9} / L\right)$ & $15(2-251)$ \\
\hline$L D H(U / L)$ & $2028(269-8358)$ \\
\hline Non continuous variables & N patients/total (\%) \\
\hline Idiopathic TTP & $80 / 114(70.2 \%)$ \\
\hline Non-diopathic TTP & $34 / 114(29.8 \%)$ \\
\hline Autoimmune disease & $17 / 114(14.9 \%)$ \\
\hline Infection & $9 / 114(7.9 \%)$ \\
\hline Pregnancy ${ }^{* *}$ & $6 / 55(10.9 \%)$ \\
\hline Drugs ${ }^{* * *}$ & $2 / 114(1.7 \%)$ \\
\hline Positive anti-ADAMTS13 IgG & $95 / 112(84.8 \%)$ \\
\hline Schistocytes & $96 / 107(89.7 \%)$ \\
\hline Neurological disorders & $65 / 109(59.6 \%)$ \\
\hline Headache & $37 / 109$ (33.9\%) \\
\hline Confusion & $22 / 109(20.2 \%)$ \\
\hline Seizure & $2 / 109(1.8 \%)$ \\
\hline Coma & $7 / 109$ (6.4\%) \\
\hline Focal deficiency & $8 / 109(7.3 \%)$ \\
\hline Proteinuria & $23 / 109(21.1 \%)$ \\
\hline Hemoglobinuria & $16 / 109(14.7 \%)$ \\
\hline At least one relapse & $31 / 114(27.2 \%)$ \\
\hline TTP related death & $1 / 114(0.9 \%)$ \\
\hline
\end{tabular}

Continuous variables data are presented as median (min - max); categorical variables are presented as n/number of patients where data was available, and percentage. LDH: lactate deshydrogenase. TTP: thrombotic thrombocytopenic purpura. ADAMTS13: a disintegrin and metalloprotease with thrombospondin type 1 repeats, member $13 .{ }^{*}$ One hundred and nine adults and 5 children ( $4<15$ years old and $1>15$ years old). ${ }^{* *}$ Fifty-five women aged 15 to 45. ${ }^{* *}$ Three patients had non-idiopathic TTP associated with drugs: interferon-beta $(n=1)$ and cocain $(n=1)$.

II) VWF multimeric analysis - VWF:CB 
VWF:Ag levels measured in our TTP patients ranged from subnormal values (min: $48 \mathrm{IU} / \mathrm{dL}$ ) to frank excess (max: $526 \mathrm{IU} / \mathrm{dL}$ ) with a median value of $146 \mathrm{IU} / \mathrm{dL}$. The $9 \mathrm{USS}$ patients however showed levels roughly within normal range, with median level measured at 100 $\mathrm{IU} / \mathrm{dL}$ (range $56-174 \mathrm{IU} / \mathrm{dL}$ ) (Table 2).

Table 2. Levels of VWF:Ag and VWF:CB in 123 patients with thrombotic thrombocytopenic purpura (TTP) (114 acquired TTP (aTTP) and 9 Upshaw-Schulman Syndrome (USS)).

\begin{tabular}{l|cccc}
\hline \multirow{2}{*}{} & \multicolumn{2}{|c}{ VWF:Ag (IU/dL) } & \multicolumn{2}{c}{ VWF:CB (IU/dL) } \\
\cline { 2 - 5 } & A-TTP $(\mathbf{n}=\mathbf{1 1 4})$ & USS ( $\mathbf{n = 9 )}$ & A-TTP ( $\mathbf{n = 1 1 4})$ & USS (n = 9) \\
\hline Median & 146 & 100 & 74 & 116 \\
Maximum & 48 & 56 & 7 & 69 \\
Interquartile Range & 526 & 174 & 299 & 139 \\
& 122 & 49 & 74 & 24 \\
\hline
\end{tabular}

VWF multimeric analysis was performed on normal pooled plasma and mean HMWM fraction was estimated at $37.3 \% \pm 5,6 \%$ ) while VWF:Ag was measured at $100 \mathrm{IU} / \mathrm{dL}$, thus mean VWF-HMWM was assessed at $37.3 \mathrm{IU} / \mathrm{dL}$. We used this value as our cut-off value for the loss of VWF-HMWM. Cut-off value of VWF:CB was fixed at $70 \mathrm{lU} / \mathrm{dL}$, in accordance with the recommendations of the French National Center for von Willebrand Disease [10].

Our TTP patients showed wide heterogeneity, ranging from severe loss to pronounced excess of VWF-HMWM. The median level was $36.9 \mathrm{IU} / \mathrm{dL}$ (range $3.2-206.8 \mathrm{lU} / \mathrm{dL}$ ). Fiftyseven $(57 / 114,50 \%)$ of them showed levels below $37.3 \mathrm{UI} / \mathrm{dL}$. As expected, remission USS patients showed marked excess of VWF-HMWM levels with median level calculated at 57.4 $\mathrm{IU} / \mathrm{dL}$ (range $34.5-71.7 \mathrm{IU} / \mathrm{dL}$ ) (Figure 1). 


\section{Figure 1}
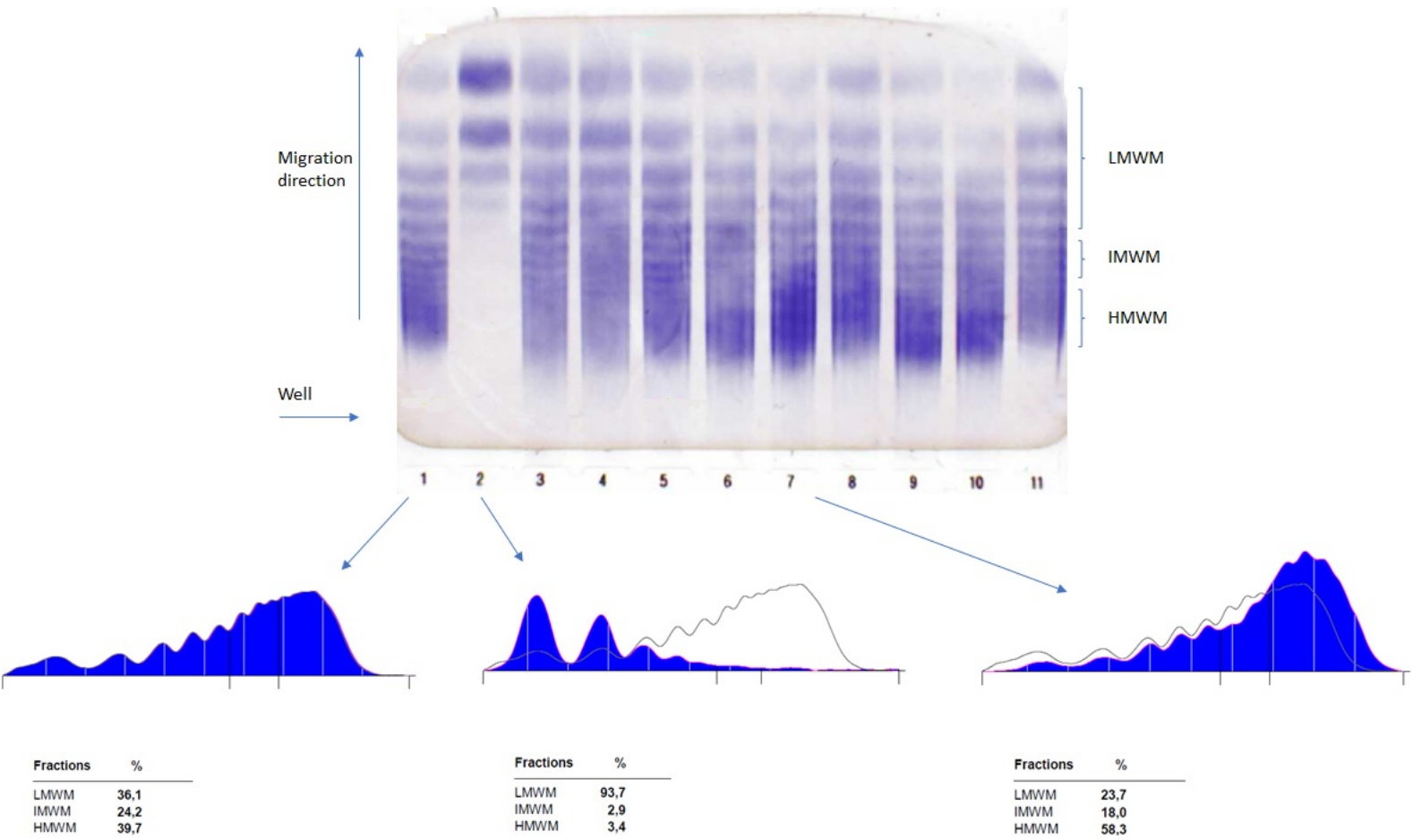

Figure 1. Multimeric distribution of VWF multimers in 8 patients with TTP.

LMWM: low molecular weight multimers; IMWM: intermediate molecular weight multimers; HMWM: high molecular weight multimers. Lanes 1 and 11: Normal pooled plasma showing normal VWF multimeric distribution. Lane 2: Patient with von Willebrand disease type 2A used as control for a significant defect of VWF-HMWM. Lanes 3 to 10: Patients with TTP. To show the densitometry analysis, the TTP patient from lane 7, showed as an example, exhibits an excess of VWF-HMWM.

These results are supported by similar findings as to VWF:CB levels: median level in the 114 TTP patients was $74 \mathrm{IU} / \mathrm{dL}$, ranging from $7 \mathrm{IU} / \mathrm{dL}$ to $299 \mathrm{IU} / \mathrm{dL}$, and 54 patients $(54 / 114$, 47.4\%) showed VWF:CB $<70 \mathrm{IU} / \mathrm{dL}$, thus indicating a loss of VWF-HMWM. Median VWF:CB level was $116 \mathrm{IU} / \mathrm{dL}$ in the 9 USS patients (range $69 \mathrm{IU} / \mathrm{dL}-139 \mathrm{IU} / \mathrm{dL}$ ), indicating an overall excess of VWF-HMWM consistent with the congenital deficiency in ADAMTS13 (Table 2).

Linear correlation performed between VWF-HMWM levels assessed by electrophoresis and VWF:CB measured by ELISA reached statistical significance $\left(r^{2}=0.5979, p<0.0001\right)$, reinforcing the concept of overlap between those two parameters (Figure 2). 


\section{Figure 2.}

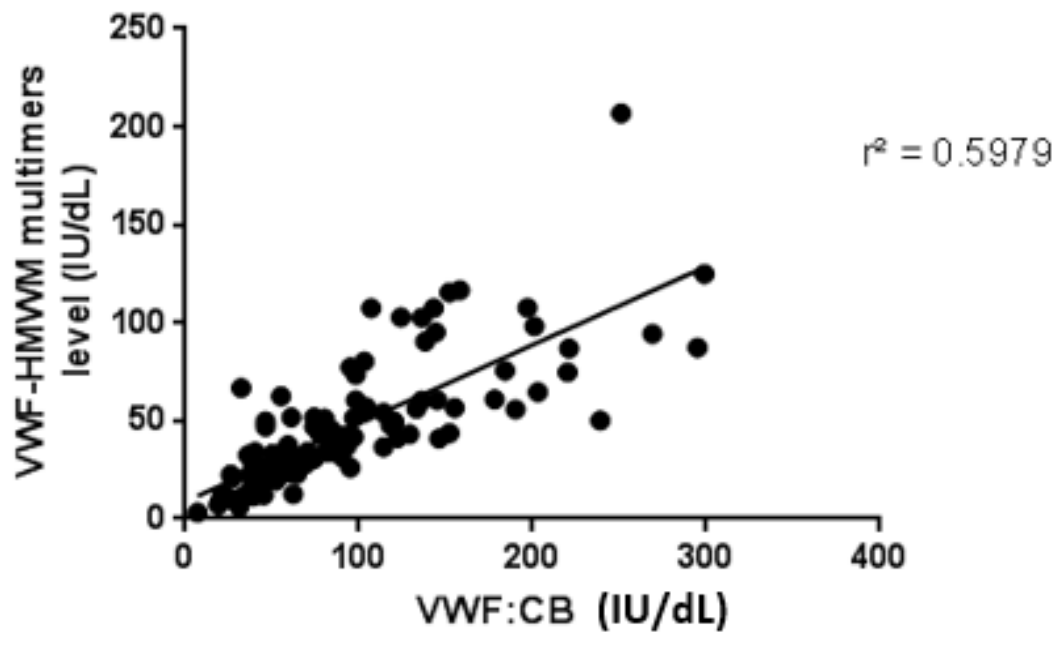

Figure 2. Linear correlation between VWF:CB and VWF-HMWM levels performed in 123 patients with TTP (114 acquired TTP and 9 USS).

VWF-HMWM: high molecular weight multimers of von Willebrand Factor; VWF:CB: von Willebrand Factor collagen binding capacity.

Correlation coefficient calculated with Pearson's formula was $r=0.5979, p<0.0001$.

\section{III) Clinical comparison}

We cross-referenced clinical and biological data from the medical records of the 114 acquired TTP patients, to VWF:CB and VWF-HMWM levels. We considered age, sex, neurological symptoms (defined as mild if comprising headache and/or confusion and severe if the patient exhibit at least one of the following: convulsions, coma, cerebral ischemia), acute kidney failure, hemoglobin level, platelet count, detectable anti-ADAMTS13 IgG and the occurrence of relapse.

VWF:CB cut-off value was set at $70 \mathrm{IU} / \mathrm{dL}$, with 54 TTP patients exhibiting VWF:CB $<70$ $\mathrm{IU} / \mathrm{dL}$ and 60 patients exhibiting VWF:CB $>70 \mathrm{IU} / \mathrm{dL}$. Neurological symptoms were associated with lower VWF:CB $(p<0.05)$ (Figure 3$)$. The same association is brought to light when splitting patients into no neurological symptoms, mild neurological symptoms and severe neurological symptoms, the latter being markedly more frequent within the VWF:CB $<70 \mathrm{IU} / \mathrm{dL}$ group $(\mathrm{p}<0.05$ ) (figure $3 \mathrm{~A})$. Neurological symptoms data were available in 109 of our 114 patients, and within the 51 who had VWF:CB $<70 \mathrm{IU} / \mathrm{dL}, 36(36 / 51=70.6 \%)$ exhibited such sign $(13 / 51=25.6 \%$ only had minor symptoms while $23 / 51=45.0 \%$ had at least one severe neurological symptom). However, amongst the 58 patients showing 
VWF:CB $>70 \mathrm{IU} / \mathrm{dL}$, only $29(29 / 58=50 \%)$ exhibited any form of neurological symptoms $(15 / 58,25.9 \%$ only experienced mild symptoms while $14 / 58,24.1 \%$ were diagnosed with at least one severe neurological symptom).

This association with neurological features is even more marked if the cut-off value for VWF:CB is set at $100 \mathrm{IU} / \mathrm{dL}(\mathrm{VWF}: \mathrm{CB}<100 \mathrm{IU} / \mathrm{dL}, \mathrm{n}=77$; VWF:CB $>100 \mathrm{IU} / \mathrm{dL}, \mathrm{n}=37$ ), with lowered $p$ values (respectively $p<0.001$ if considering neurological symptoms as opposed to no neurological symptoms ; $p<0.01$ if considering the severity of neurological symptoms) (Figure 3B). VWF-HMWM level cut-off value was set at $37.3 \mathrm{IU} / \mathrm{dL}$, according to our experiments on normal pooled plasma, with 56 patients having HMW-VWF multimers level $<37.3 \mathrm{IU} / \mathrm{dL}$ and 58 patients HMW-VWF multimers level $>37.3 \mathrm{IU} / \mathrm{dL}$. Similarly than with the VWF:CB cut off set at $70 \mathrm{IU} / \mathrm{dL}$, our study shows an association between the loss of VWFHMWM and neurological impairment. Out of the 109 patients for which neurological symptoms data were available, 51 had VWF-HMWM level $<37.3 \mathrm{IU} / \mathrm{dL}, 36$ of which had neurological symptoms (36/51: 70.5\%) : 13 exhibited mild symptoms (13/51:25.5\%) while $23(23 / 51: 45.0 \%)$ experienced severe neurological symptoms. In the 58 remaining patients with VWF-HMWM level $>37.3 \mathrm{IU} / \mathrm{dL}$, only 29 experienced neurological symptoms $(29 / 58$ : $50 \%$ ) with roughly half with mild and half with severe symptoms (respectively $15 / 58=29.9 \%$ and $14 / 58=24.1 \%)(p<0.05)$ (figure $3 C$ ). 


\section{Figure 3}
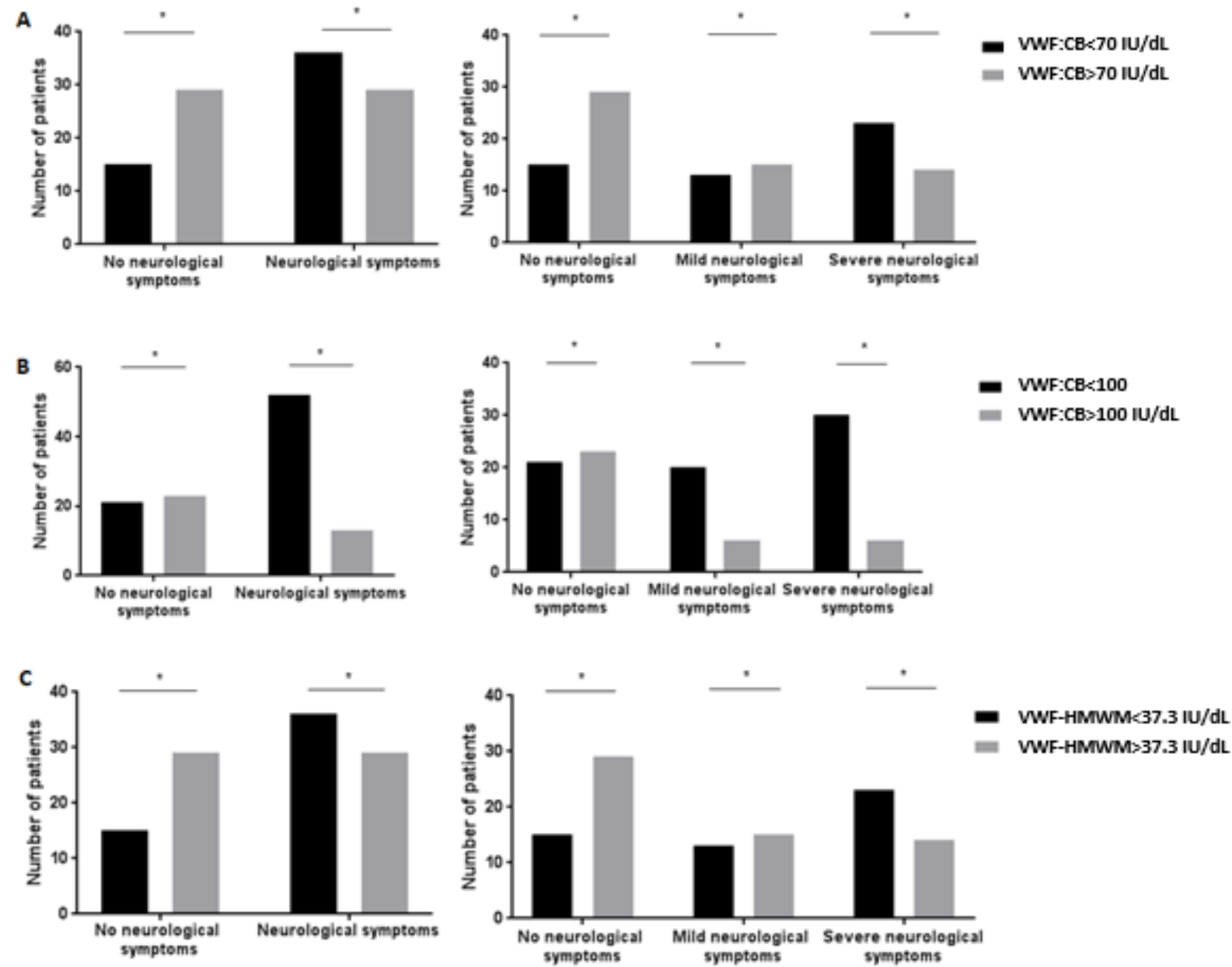

Figure 3. Correlation of neurological symptoms with VWF:CB and VWF-HMWM level in 114 acquired TTP patients.

Neurological symptoms in 114 acquired TTP patients are more frequent in lowered VWF:CB group compared to normal or elevated VWF:CB group, (A) VWF:CB cut-off set at $70 \mathrm{IU} / \mathrm{dL}$ and (B) VWF:CB cut-off set at $100 \mathrm{lU} / \mathrm{dL}$ (lowest and highest values for VWF-CB assay as stated by the French National Reference Center for von Willebrand Disease [10]). Neurological symptoms in 114 acquired TTP patients are more frequent in lowered VWFHMWM level group compared to elevated VWF-HMWM levels (C) (cut-off value: $37.3 \mathrm{IU} / \mathrm{dL}$ ). *: $p<0.05$; ${ }^{* *}: p<0.01$; ${ }^{* *}: p<0.001$. Mild neurological symptoms: headache and/or confusion. Severe neurological symptoms: seizure, coma, cerebral ischemia. 
VWF:CB $<70 \mathrm{IU} / \mathrm{dL}$ was also associated with deeper thrombocytopenia: mean platelet count in the VWF:CB $<70 \mathrm{IU} / \mathrm{dL}$ group was $17 \times 10^{9} / \mathrm{L}$ (standard deviation $15 \times 10^{9} / \mathrm{L}$ ) versus 32 $\times 10^{9} / \mathrm{L}$ (standard deviation $\left.45 \times 10^{9} / \mathrm{L}\right)$ in the VWF:CB $>70 \mathrm{IU} / \mathrm{dL}$ group $(\mathrm{p}<0.05)$ (data not shown). Unexpectedly, we found an association between VWF:CB $<70 \mathrm{IU} / \mathrm{dL}$ and positive anti-ADAMTS13 IgG. Amongst the 112 patients on 114 where this data was available, antiADAMTS13 lgG were found positive in 49 out of 53 patients with VWF:CB $<70$ IU/dL (49/53 $=92.5 \%)$ while they were only found positive in 46 of the remaining 59 patients $(46 / 59=$ $78 \%)$ with VWF:CB $>70 \mathrm{IU} / \mathrm{dL}(\mathrm{p}<0.05)$ ( Figure 4A).

As with VWF:CB, an association with positive anti-ADAMTS13 IgG and HMW-VWF multimers $<37.3 \mathrm{IU} / \mathrm{dL}$ was highlighted in this study: 52 out of 56 patients with HMW-VWF multimers $<37.3 \mathrm{IU} / \mathrm{dL}$ had positive anti-ADAMTS13 IgG (52/56:92.9\%) while only 43 of the remaining 56 patients with HMW-VWF multimers $>37.3 \mathrm{IU} / \mathrm{dL}$ had such profile $(46 / 56=$ $76.8 \%)(p<0.05)$ (Figure 4B).

\section{Figure 4.}
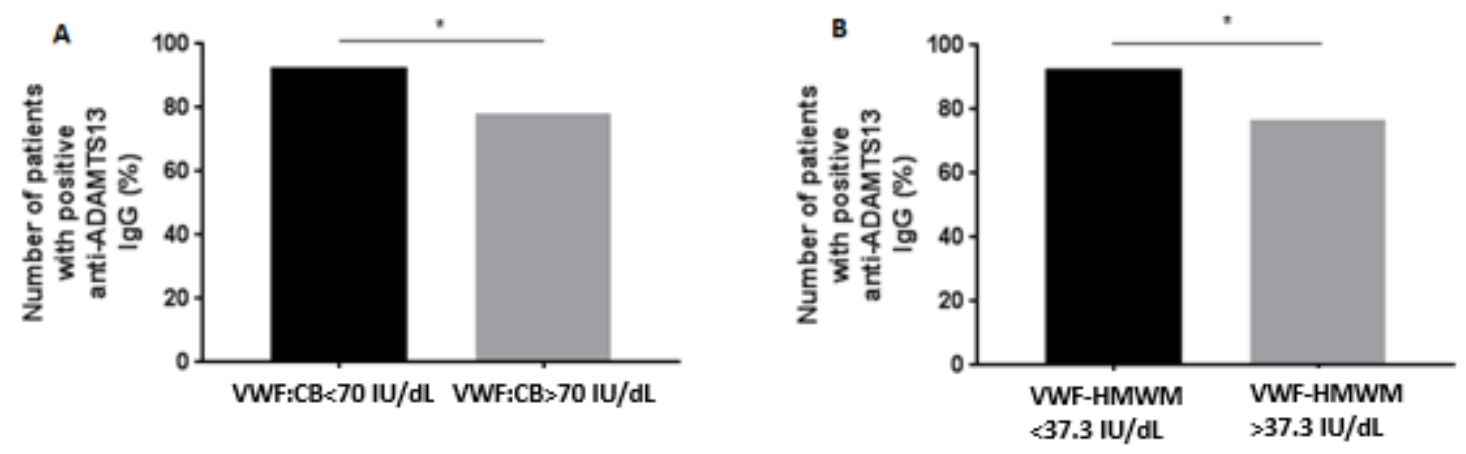

Figure 4. Correlation of detectable anti-ADAMTS13 IgG with VWF:CB and VWF-HMWM in 114 acquired TTP patients.

VWF :CB $<70 \mathrm{IU} / \mathrm{dL}(\mathrm{A})$ and VWF-HMWM $<37.3 \mathrm{IU} / \mathrm{dL}$ (B) are associated with more frequent positive anti-ADAMTS13 IgG. * $p<0.05$

No association was found between platelet count and VWF-HMWM levels, and no association was found between sex, age, hemoglobin, acute kidney failure, the occurrence of a relapse and both VWF:CB and VWF-HMWM (data not shown). 


\section{Discussion}

This study focusing on acquired TTP shows that VWF-HMWM could partially explain the clinical variability exhibited by TTP patients, and that VWF-HMWM can satisfactorily be assessed by VWF:CB, much easier to carry out than electrophoresis.

Demographic, biological and clinical data are consistent with previous descriptions of large TTP cohorts $[14,15,16,17]$, with however an apparent over-representation of idiopathic TTP, probably related to the exclusion criteria of our study.

USS patients exhibited as expected high levels of VWF-HMWM and higher than normal VWF:CB, consistent with the constant excess of HMW due to the genetic deficiency of ADAMTS13. These profiles were used as internal control to evaluate the performances of both electrophoresis and ELISA to detect and quantify VWF-HMWM excess. However, these USS patients (well documented and monitored) regularly undergo prophylactic plasmapheresis, which could explain why some of them appear to have normal levels of both VWF:CB and VWF-HMWM.

The first aim of this work was to establish a correlation between VWF:CB and VWF-HMWM levels as methods to detect and quantify either a loss or an excess of VWF-HMWM. Our study suggests that VWF:CB is indeed a good reflect of the multimeric distribution of VWF, and as it is both much easier to carry-out and less time consuming than electrophoresis, it could replace satisfactorily the latter reference method.

Clinical and biological comparisons showed that decreased VWF-HMWM levels were associated with the presence and the severity of neurological symptoms and positive antiADAMTS13 lgG; decreased VWF:CB showed similar results with the addition of an association with low platelet count. It is surprising that this result is only found with VWF:CB and not with VWF-HMWM levels, and we can assume that the relatively small number of patients enrolled could not reach statistical significance. We do not however find an association between VWF-HMWM and the occurrence of a relapse, suggesting that VWFHMWM may only be associated with the ongoing acute phase and not predict future evolution.

Studies on multimeric distribution of VWF in acquired TTP are very scarce, notably because of the technical complexity inherent in VWF multimer analysis. Moake and colleagues reached a milestone in deciphering the pathophysiology of TTP in 1982 when they reported the presence of unusually large VWF-HMWM in 4 probable USS patients and demonstrated the loss of VWF-HMWM during acute TTP episodes, thus paving the way for the discovery of ADAMTS13 [18]. This study did not, however, look into the relationship between VWFHMWM and clinical features. The prospective study conducted by Veyradier and colleagues 
in 2001 on the role of ADAMTS13 in 111 cases of TMA (including 66 TTP) highlighted the vast heterogeneity of VWF multimeric distribution in TTP [12] (with roughly similar results to ours), without focusing on the potential clinical impact of VWF-HMWM. Both studies used complex in house-methods, with superior resolution and certainly a better assessment of the VWF-HMWM than the semi-automated method we used. Nonetheless, the relative ease of our method allowed us to study a quite large number of patients.

Our results suggest that acquired auto-immune TTP lead to more decreased levels of VWFHMWM compared to non-autoimmune acquired TTP. This apparent decrease can probably be explained by a sequestration of these VWF-HMWM within the microthrombi, which are therefore not free in plasma. We can hypothesize that acquired auto-immune TTP could have a different development kinetic compared to other etiologies. Rapid formation of microthrombi leading to both deeper consumption thrombocytopenia and decreased VWFHMWM with faster advent of neurological symptoms in acquired auto-immune TTP could explain our results. This is further supported by a previous study on acquired TTP suggesting that TTP patients with detectable anti-ADAMTS13 IgG display a worse prognosis [19].

Although our results appear to demonstrate an association between VWF-HMWM and the clinical presentation of acquired TTP, we do not believe that the assessment of the multimeric distribution of VWF is relevant as a diagnostic or prognostic tool. It was merely used in our study as a proof of concept to understand underlying mechanisms in acquired TTP.

To our knowledge, this is the first study to focus on VWF-HMWM levels rather than percentage, and to focus on the relevance of VWF-HMWM on the clinical presentation of acquired TTP. A further study looking into a potential link between VWF-HMWM and cardiac symptoms, troponin levels and treatment could substantiate this work. Our results may offer new insights to understanding the pathophysiology of acquired auto-immune TTP.

\section{Funding}

This study was partially supported by the PHRC AOM05012 «ADAMTS13 dependent prognostic factors in adult and child onset thrombotic thrombocytopenic purpura », DRCD, AP-HP.

Conflict of interest: none. 


\section{Appendix :}

The members of the Reference Center for Thrombotic Microangiopathies (CNR-MAT) are: Augusto Jean-François (Service de Néphrologie, dialyse et transplantation ; CHU Larrey, Angers); Azoulay Elie (Service de Réanimation Médicale, Hôpital Saint-Louis, Paris); Barbay Virginie (Laboratoire d'Hématologie, CHU Charles Nicolle, Rouen); Benhamou Ygal (Service de Médecine Interne, CHU Charles Nicolle, Rouen); Bordessoule Dominique (Service d'Hématologie, Hôpital Dupuytren, Limoges); Boyer Olivia (Service de Néphrologie Pédiatrique, Hôpital Necker) ; Charasse Christophe (Service de Néphrologie, Centre Hospitalier de Saint-Brieuc); Charvet-Rumpler Anne (Service d'Hématologie, CHU de Dijon) ; Chauveau Dominique (Service de Néphrologie et Immunologie Clinique, CHU Rangueil, Toulouse); Choukroun Gabriel (Service de Néphrologie, Hôpital Sud, Amiens); Coindre JeanPhilippe (Service de Néphrologie, CH Le Mans); Coppo Paul (Service d'Hématologie, Hôpital Saint-Antoine, Paris); Corre Elise (Service d'Hématologie, Hôpital Saint-Antoine, Paris); Delmas Yahsou (Service de Néphrologie, Hôpital Pellegrin, Bordeaux); Deschenes Georges (Service de Néphrologie Pédiatrique, Hôpital Robert Debré, Paris); Devidas Alain (Service d'Hématologie, Hôpital Sud-Francilien, Corbeil-Essonnes); Dossier Antoine (Service de Néphrologie, Hôpital Bichat, Paris); Dossier Claire (Service de Néphrologie Pédiatrique, Hôpital Robert Debré, Paris); Fain Olivier (Service de Médecine Interne, Hôpital SaintAntoine, Paris); Fakhouri Fadi (Service de Néphrologie, CHU Hôtel-Dieu, Nantes) ; Frémeaux-Bacchi Véronique (Laboratoire d'Immunologie, Hôpital Européen Georges Pompidou, Paris); Galicier Lionel (Service d'Immunopathologie, Hôpital Saint-Louis, Paris); Grangé Steven (Service de Réanimation Médicale, CHU Charles Nicolle, Rouen) ; Guidet Bertrand (Service de Réanimation Médicale, Hôpital Saint-Antoine, Paris); Halimi JeanMichel (Service de Néphrologie Pédiatrique, Hôpital Bretonneau, Tours); Hamidou Mohamed (Service de Médecine Interne, Hôtel-Dieu, Nantes); Herbrecht Raoul (service d'Oncologie et d'Hématologie, Hôpital de Hautepierre, Strasbourg); Hié Miguel (Service de Médecine Interne, Groupe Hospitalier Pitié-Salpétrière, Paris) ; Jacobs Frédéric (Service de Réanimation Médicale, Hôpital Antoine Béclère, Clamart); Joly Bérangère (Service d'Hématologie Biologique, Hôpital Lariboisière, Paris) ; Kanouni Tarik (Unité d'Hémaphrèse, Service d'Hématologie, CHU de Montpellier) ; Kaplanski Gilles (Service de Médecine Interne, Hôpital la Conception, Marseille) ; Lautrette Alexandre (Service de Néphrologie Pédiatrique B, Hôpital Hôtel-Dieu, Clermont-Ferrand); Le Guern Véronique (Unité d'Hémaphérèse, Service de Médecine Interne, Hôpital Cochin, Paris) ; Lequintrec Moglie (Service de Néphrologie, CHU de Montpellier) ; Loirat Chantal (Service de Néphrologie Pédiatrique, Hôpital Robert Debré, Paris); Moulin Bruno (Service de Néphrologie, Hôpital Civil, Strasbourg); Mousson Christiane (Service de Néphrologie, CHU de Dijon); Ojeda Uribe Mario (Service d'Hématologie, Hôpital Emile Muller, Mulhouse); Ouchenir Abdelkader 
(Service de Réanimation, Hôpital Louis Pasteur, Le Coudray); Parquet Nathalie (Unité de Clinique Transfusionnelle, Hôpital Cochin, Paris); Peltier Julie (Urgences Néphrologiques et Transplantation Rénale, Hôpital Tenon, Paris) ; Pène Frédéric (Service de Réanimation Médicale, Hôpital Cochin, Paris) ; Perez Pierre (Service de Réanimation polyvalente, CHU de Nancy) ; Poullin Pascale (Service d'hémaphérèse et d'autotransfusion, Hôpital la Conception, Marseille); Pouteil-Noble Claire (Service de Néphrologie, CHU Lyon-Sud, Lyon); Presne Claire (Service de Néphrologie, Hôpital Nord, Amiens); Provôt François (Service de Néphrologie, Hôpital Albert Calmette, Lille); Rondeau Eric (Urgences Néphrologiques et Transplantation Rénale, Hôpital Tenon, Paris); Saheb Samir (Unité d'Hémaphérèse, Hôpital la Pitié-Salpétrière, Paris) ; Schlemmer Benoît (Service de Réanimation Médicale, Hôpital Saint-Louis, Paris); Seguin Amélie (Service de Réanimation Médicale, centre hospitalier de Vendée) ; Servais Aude (Service de Néphrologie, CHU Necker-Enfants Malades); Stépanian Alain (Laboratoire d'Hématologie, Hôpital Lariboisière, Paris); Vernant Jean-Paul (Service d'Hématologie, Hôpital la Pitié-Salpétrière, Paris); Veyradier Agnès (Service d'Hématologie Biologique, Hôpital Lariboisière, Paris); Vigneau Cécile (Service de Néphrologie, Hôpital Pontchaillou, Rennes); Wynckel Alain (Service de Néphrologie, Hôpital Maison Blanche, Reims); Zuber Julien (Service de Néphrologie, CHU Necker-Enfants Malades); Zunic Patricia (Service d'Hématologie, Groupe Hospitalier Sud-Réunion, la Réunion).

\section{Conflict of interest}

None

\section{References}

1. Sadler JE. Von Willebrand factor, ADAMTS13, and thrombotic thrombocytopenic purpura. Blood. 2008;112(1):11-18.

2. Furlan M, Robles R, Galbusera M, et al. Von Willebrand Factor-Cleaving Protease in Thrombotic Thrombocytopenis Purpura and the Hemolytic-Uremic Syndrome. The New England Journal of Medicine. 1998;339(22):1578-1584.

3. Peyvandi F, Lavoretano S, Palla R, et al. ADAMTS13 and anti-ADAMTS13 antibodies as markers for recurrence of acquired thrombotic thrombocytopenic purpura during remission. Haematologica. 2008;93(2):232-239.

4. Levy GG, Nichols WC, Lian EC, et al. Mutations in a member of the ADAMTS gene family cause thrombotic thrombocytopenic purpura. Nature. 2001;413(6855):488-494.

5. Tsai H-M, Lian EC. Antibodies to Von Willebrand Factor-Cleaving protease in acute TTP. New England Journal of Medicine. 1998;339(22):1585-1594.

6. Joly BS, Coppo P, Veyradier A. Thrombotic thrombocytopenic purpura. Blood. 2017;129(21):2836-2846. 
7. Kremer Hovinga JA, Coppo P, Lämmle B, et al. Thrombotic thrombocytopenic purpura. Nature Review Disease Primers. 2017;3:17020.

8. Stockschlaeder M, Schneppenheim R, Budde U. Update on von Willebrand factor multimers $\square$ : focus on high- molecular-weight multimers and their role in hemostasis. Blood Coagulation and Fibrinolysis. 2014;25(3):206-216.

9. Sadler JE, Budde U, Eikenboom C, et al. Update on the pathophysiology and classification of von Willebrand disease : a report of the Subcommittee on von Willebrand Factor. Journal of Thrombosis and Haemostasis. 2006;4(10):2103-2114.

10. Veyradier A, Boisseau P, Fressinaud E, et al. A Laboratory Phenotype / Genotype Correlation of 1167 French Patients from 670 Families with von Willebrand Disease. Medicine. 2016;95(11):1-11.

11. Favaloro EJ. Utility of the von Willebrand factor collagen binding assay in the diagnosis of von Willebrand disease. American Journal of Hematology. 2017;92(1):114-118.

12. Veyradier A, Obert B, Houllier A, et al. Specific von Willebrand factor-cleaving protease in thrombotic microangiopathies: A study of 111 cases. Blood. 2001;98(6):1765-1772.

13. Kokame K, Nobe $\mathrm{Y}$, Kokubo $\mathrm{Y}$, et al. FRETS-VWF73, a first fluorogenic substrate for ADAMTS13 assay. British Journal of Haematology. 2005;129(1):93-100.

14. Mariotte E, Azoulay E, Galicier L, et al. Epidemiology and pathophysiology of adulthood-onset thrombotic microangiopathy with severe ADAMTS13 deficiency (thrombotic thrombocytopenic purpura): a cross-sectional analysis of the French national registry for thrombotic microangiopathy. Lancet Haematology. 2016;3(5):237245.

15. Scully M, Yarranton H, Cavenagh J, et al. Regional UK TTP Registry $\square$ : correlation with laboratory ADAMTS 13 analysis and clinical features. British Journal of Haematology. 2008;142(5):819-826.

16. Fujimura $\mathrm{Y}$, Matsumoto M. Registry of 919 Patients with Thrombotic Microangiopathies across Japan $\square$ : Database of Nara Medical University during 19982008. Internal Medicine. 2009;49(1):7-15.

17. George JN, Hovinga JAK, Terrell DR, et al. The Oklahoma Thrombotic Thrombocytopenic Purpura - Hemolytic Uremic Syndrome Registry $\square$ : the Swiss connection. European Journal of Haematology. 2008;80(4):277-286.

18. Moake JL, Rudy CK, Troll JH et al. Unusually large plasma factor VIII:Von Willebrand Factor multimers in chronic relapsing thrombotic thrombocytopenic purpura. New England Journal of Medicine. 1982;307(23):1432-1435.

19. Coppo P, Wolf M, Veyradier A et al. Prognostic value of inhibitory anti-ADAMTS13 
antibodies in adult-acquired thrombotic thrombocytopenic purpura. British Journal of Haematology. 2006;132(1):66-74. 